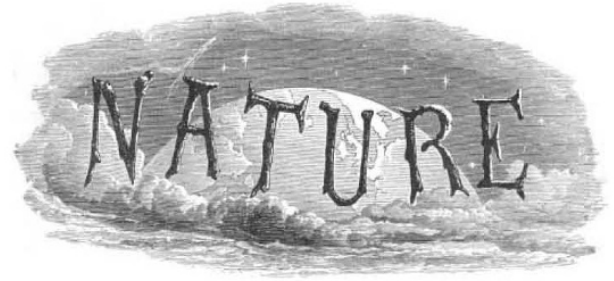

SATURDAY, JULY 30, I932

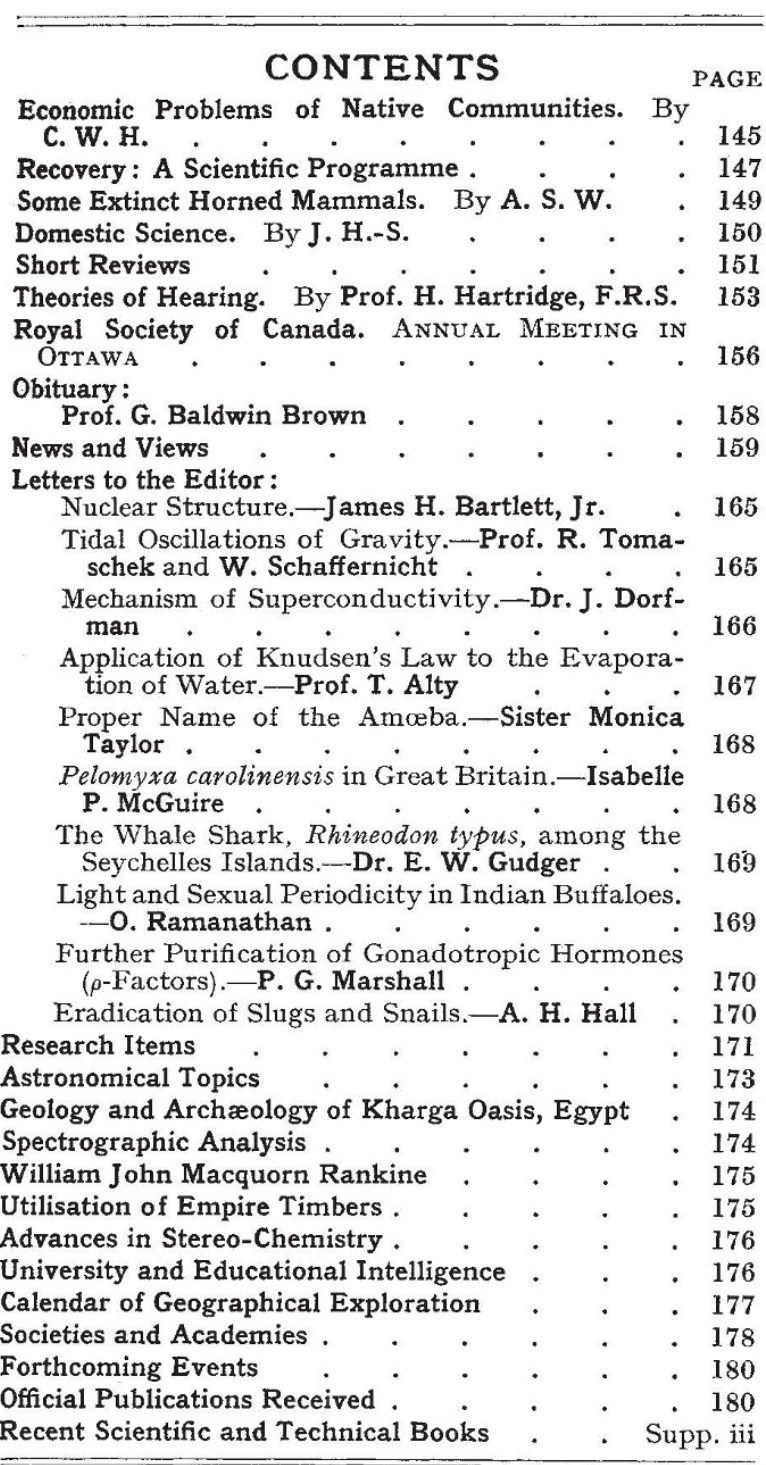

Editorial and Publishing Offices:

MACMILLAN \& CO., LTD.

ST. MARTIN'S STREET, LONDON, W.C. 2

Telephone Number: WHITEHALL 8831

Telegraphic Address. PHUSIS, LESQUARE, LONDON

Advertisements should be addressed to

T. G. Scott \& Son, Ltd., 63 Ludgate Hill, London, E.C. 4

Telephone Number: City 1266

\section{Economic Problems of Native Communities}

7 HE East African group of British colonies and dependencies has, during the last few years, had to endure a series of Government commissions, all undertaken with great pains and conducted by able chairmen. One of their main objects has been to determine the course of the political evolution of these regions, and the net results have been alternately to excite and depress the political aspirations of the resident European and Asiatic community, but the reflex effect on the more sophisticated section of the overwhelming black population cannot have been to its advantage.

The commissions culminated in a prolonged inquiry carried out by a Joint Committee of both Houses of Parliament sitting in London and presided over by the late Lord Stanley of Alderley, and after his lamented death, by Lord Onslow. This was a momentous business ; it went on for some months and issued a monumental and wellbalanced report. But inquiry was not yet to cease, for arising out of this Joint Committee is the report by Lord Moyne which is now before us ; ${ }^{*}$ one on railway economics, one on the financial position of Tanganyika Territory, and the Morris-Carter Land Commission are yet to come as sequelæ of the Joint Committee.

After the considerable expenditure of public funds involved by these extensive inquiries, it was pleasing to hear the Secretary of State for the Colonies recently declare, at the annual East African dinner, that inquiry had been overdone and would henceforth cease. Lord Moyne's report is, however, an admirable document; it is short, and it goes to the heart of things, namely, the economic position of the Colony. The old country, the heart of reserves of centuries of capital accumulation, has been shaken to its foundations during the last two years ; the marvel therefore is that the colonies, all dependent on the production of raw materials which have slumped below cost of production, can have survived at all.

The main objects of Lord Moyne's inquiry were to ascertain the contribution made to taxation by the different racial communities, to review railway freights and import duties, and thus discover the extent to which each community in the colony benefits or suffers. Further, to ascertain as nearly as possible the amount of public money expended on natives and non-natives, and to what extent financial responsibility should be conferred on

* Report by the Financial Commissioner (Lord Moyne) on Certain Questions in Kenya. (Cmd. 4093.) Pp. vit122. (London: H.M. Stationery Office, 1932.) $2 s$.

No. 3274 , VoL. 130] 
Native Councils. Lastly, to consider the general and economic situation in Kenya.

Lord Moyne approached his inquiry in an unbiased fashion, and conducted his mission with great rapidity; he has produced a document which it is impossible to controvert, and which should do much to dissipate a cloud of misinformation which has of late tended to obscure the situation.

Lord Moyne deals in detail with the incidence of the Hut and Poll Tax, which has up to now been the somewhat rough-and-ready way by which the native population of the country has made its contribution to the revenue. He puts his finger on the weak points of this system, and demonstrates how increasingly difficult it has become, particularly in some of the more remote districts, for natives to obtain the cash since the great slump in the values of produce occurred. He goes on to demonstrate how this fall in values has crippled the purchasing power of the natives, and so trade, generally, has greatly declined. The inequality, the inelasticity of this form of taxation, its lack of relation to prices of raw material, produced a considerable impression upon his financial mind, and he, moreover, pertinently remarks that "natives pay their tax not out of a fixed income but by means of additional production in the Reserves or alternately they may choose to earn the money by work in settled areas". For these reserves Lord Moyne recommends that the hut tax should eventually be replaced by a cultivation tax, that the poll tax should be a fixed sum, and in addition, there should be a live stock tax. There is much to be said for these proposals, but he does not appear to have considered fully the great increase of fiscal machinery these changes will involve when dealing with vast numbers of small cultivated plots. $\mathrm{He}$ next analyses the railway rates policy, and comes to the conclusion that their incidence is generally fair as between the racial communities. The same conclusion is also arrived at with regard to the incidence of import duties.

Perhaps the most difficult part of Lord Moyne's survey was the attempt to assess the amount of money expended in the interests of each community; and the impossibility of earrying out this aim with a great degree of accuracy is freely acknowledged. It is pointed out that the costs of various services, such as, for example, military and police, must be shown under general heads, for they benefit all communities. The plan of making two arbitrary divisions was thus adopted, namely, divisible and indivisible services. Even when this has been done, contrasts between racial standards of life make the measure of equality of sacrifice in taxation even more difficult of assessment. Lord Moyne frankly admits that he has formed the opinion that "in the development of the undivided services in Kenya there has been a bias towards the conveniences of a civilisation in which the native so far shares little of the direct advantages ". But he goes on to make it clear that there is no suggestion that the European community has taken unfair advantage of their opportunity; it was, however, only to be expected when on one side we find a well-organised, politically-minded body of Europeans and on the other a mass of Africans only faintly articulate and with a weak representation on the Legislative Council. But after considering every factor in the case, as Lord Moyne realises, it is not even then easy to assess a fair proportion of expenditure for each section.

In 1931 each European contributed nearly £29 to the revenue of the Colony and each native contributed 5 shillings ; the individual gap is immense. The aggregate contributed by some 17,285 Europeans is 1665,780 and that contributed by some $2,950,000$ natives is $£ 791,100$, and the amount spent directly on the European community is about $£ 171,250$ and on the African $£ 332,000$. The difficulty of comparison is due to the fact that the bare standard of service necessary for Europeans can bear little relation to that necessary for Africans.

The greatest problem at present in all African countries is to raise the culture level of the native; it was rising slowly up to the occurrence of the worldwide depression, and was mainly due to the progress of the activities resultant on white settlement ; and when prices rally this progress will be resumed. A rise in the culture stage of the native, however, cannot be delayed, and it is essential to educate him to the widest extent in the practical art of life, so that he may obtain a better yield from his land and conserve and improve its agricultural value, instead of ruining it as he is doing at present. If this can be achieved, we shall fully justify our presence in Africa. At the same time, with the progress of the prosperity of the village the native cannot fail to develop sociologically. The African to-day is avid for education, but too often confines himself to a desire to read and write.

In order to ensure a definite provision for steady progress in education, agricultural training, and medical hygiene, we find the recommendation that one-half of the revenue obtained from native direct taxation should be placed each year in what is termed a Native Betterment Fund, to be adminis- 
tered by a special committee, with which natives are to be closely associated, and also representatives of the European colonists. This, if carried into effect, is a proposal which will be welcomed by native opinion and do much to demonstrate the solicitude of Government to give the natives a fair deal. The Kenya politicians may, however, plead that it is unconstitutional, as it will operate independently of the Legislative Council.

The proposal to found a Native Marketing Advisory Council is also one that is long overdue, for the victimisation of natives by Asiatic traders has for years past been a matter of concern.

Space forbids reference to many points of interest, but it is evident that, quite apart from its special reference to one Colony, Lord Moyne's report carries many lessons which are applicable to other dependencies of a similar class, for it demonstrates the importance of far-sighted discrimination in regard to local financial demands, and the necessity of firmer control than that which successive governors have, owing to political exigencies, been able to exercise in the past.

C. W. H.

\section{Recovery: A Scientific Programme}

Recovery: the Second Effort. By Sir Arthur Salter. Pp. xvi + 306. (London : G. Bell and Sons, Ltd., 1932.) $10 s .6 d$. net.

TTHERE could be few more startling contrasts 1 than that between the pedantic platitudes of the naval and military experts of the Disarmament Conference, their endless splitting of hairs, and the balanced and comprehensive survey of the events during the last thirteen years that have been mainly responsible for the present critical world position which Sir Arthur Salter gives us in his book "Recovery". Alike in his analysis and summing up of the various special problems of currency, finance, reparations and war debts, tariffs, industrial organisation, Government control and security, on which his experience as a high official of the League of Nations, as first general secretary to the Reparations Commission, and active participant in most of the international negotiations and acts in the first effort at post-war recovery render him an expert authority of the highest standing, Sir Arthur writes with a vision and a sense of values which only emphasises the narrowmindedness and inadequacy of the military and naval experts. We have been accustomed in Britain to admit such experts to positions of high administration and authority from which the scientific expert is rigidly excluded. When allow- ance has been made for Government pressure or for the absence of adequate instruction or definite policy from the Conference itself, the proceedings of the experts at the Disarmament Conference make a dismal record which may well endanger the future use of the expert in administration, in spite of the striking success which under appropriate conditions has attended the work of the expert committees of the League in health, finance, economics, transit and communications, etc.

The masterly diagnosis which Sir Arthur gives us of the causes of the world depression conveys the emphatic impression that the main cause of our present critical position is not monetary, economic, or political, but the persistent attempt to handle world problems on national and sectional linesthe same effort which, unless public opinion realises the danger in time, threatens to defeat the purpose of the Disarmament Conference. The whole book is an antidote to such small-mindedness. Writing with an essentially scientific outlook, Sir Arthur conveys not only a sense of perspective in viewing the complex reactions of the financial, industrial, economic, and political factors involved in the field of monetary policy, credit, commercial policy, economic organisation, government, and peace, but also gives us trenchant and constructive criticism which leads him to prescriptions for recovery and for a 'New World Order' set out in his concluding chapter.

To this chapter the majority of readers will turn most eagerly, and it should accordingly be noted that Sir Arthur reaches his conclusions as a result of impartial analysis of the relevant factors and a determined attempt to disentangle them from prejudice. Only in this way can we arrive at a satisfactory basis for adequate action, and this method of procedure will at once be recognised as fundamentally that of science.

Characteristic of the book is its note of confidence. Difficult as is our task, the problem facing us is, as Sir Arthur rightly reminds us, capable of human solution. "Never was Nature so prodigal in her gifts; never was man so well equipped in skill and scientific resources to utilise them." Or again, "We are, if we could but grapple with our fate, the most fortunate of the generations of men. In a single lifetime science has given us more power over Nature, and extended further the range of vision of the exploring mind, than in all recorded history. Now, and now only, our material resources, technical knowledge, and industrial skill are enough to afford to every man of the world's teeming population comfort, adequate 